\title{
Effects of Tranexamic Acid on Mortality and Blood Transfusion in Trauma Patients with Significant Hemorrhage: A Clinical Trial
}

Farzad Kakaei ${ }^{1}$, Peyman Virani ${ }^{1}$, Shahriar Hashemzadeh ${ }^{1}$, Sina Zarrintan ${ }^{1 *}$, Samad Beheshtirouy ${ }^{2}$, and Touraj Asvadi $^{1}$

1- Department of General Surgery, Tabriz University of Medical Sciences, Tabriz, Iran

2- Department of Cardiothoracic Surgery, Tabriz University of Medical Sciences, Tabriz, Iran

\begin{abstract}
Extensive hemorrhage is a significant cause of mortality in trauma patients. Tranexamic acid has been used for controlling bleeding in cardiovascular surgeries and dental manipulations in patients with hemophilia. However, in traumatic patients with bleeding, its use dates back to more recent years. This study aims to examine the effects of this drug on reducing mortality and blood transfusion rate in trauma patients with significant hemorrhage. A total of 60 patients with significant trauma-related hemorrhage (systolic blood pressure $<90 \mathrm{mmHg} / \mathrm{heart}$ rate $>$ $110 / \mathrm{min}$ ) from the emergency department of Imam Reza Hospital (Tabriz, Iran), were randomized in two groups. The case group received intravenous Tranexamic acid ( $1 \mathrm{~g}$ in $10 \mathrm{~min}$ and then $1 \mathrm{~g}$ over $8 \mathrm{~h}$ ). The control group received placebo. Rate of transfusion and rate of one-month mortality were compared between the study groups. The mean ICU stay and overall hospitalization times did not have significant difference between two groups $(p<0.05)$. Transfusion of packed cells was $6.03 \pm 1.50$ and $6.03 \pm 1.22$ units in case and control groups respectively. Transfusion of fresh frozen plasma (FFP) was $2.50 \pm 1.36$ and $3.03 \pm 0.96$ units in case and control groups respectively $(p=0.09)$. Transfusion of platelets was $0.40 \pm 0.201 .33 \pm 0.31$ units in case and control groups respectively $(p=0.01)$. Three patients $(10 \%)$ in the case group and 4 patients $(13.3 \%)$ in the control group were expired $(p=0.50)$. Tranexamic acid is safe and effective in reducing platelet transfusion rate in patients with trauma-related significant hemorrhage. However, transfusion need and mortality would not reduce by its use in trauma patients. Key Words: Trauma; Hemorrhagic shock; Tranexamic Acid; Transfusion
\end{abstract}

Corresponding author:

Sina Zarrintan, MD

Department General Surgery, Tabriz University of Medical Sciences, Tabriz, Iran

E-mail: s.zarrintan@yahoo.com

Receive date: 2017-06-02 | Accept date: 2017-09-19 | Publish date: 2017-10-01

DOI: 10.7575/aiac.abcmed.17.05.04.04 


\section{Introduction}

Trauma is the leading cause of mortality in 1-44 years-old population. Bleeding is a significant cause of death and complications in trauma patients (1). Hemostatic equilibrium is provided by processes of coagulation and fibrinolysis in traumatic patients (2). However, overactivation of fibrinolysis pathways could lead to uncontrolled hemorrhage and significant mortality (3). Hemorrhage control is achieved by surgical intervention, volume resuscitation and pharmaceutical therapies in traumatic patients. Anti-fibrinolytic agents have been successfully used to control bleeding in nontraumatic conditions. For instance, Aprotinin is an accepted drug for hemorrhage control in liver transplantation (4). However, use of antifibrinolytic agents in traumatic and traumarelated hemorrhagic shock is a novel strategy which could lessen mortality and morbidity (5, 6). A number of studies recommend that Tranexamic acid can be used safely in trauma patients to control hemorrhage and reduce mortality (7-10).

It is essential that traumatic bleeding is controlled in first ours of patients' admission $(11,12)$. Along with vital strategies of surgical interventions and volume resuscitation, antifibrinolytic agents could lessen the need for transfusion and reduce hemorrhage-related mortality (13-15). The effects of Tranexamic acid on reducing mortality in traumatic patients have been described by Shakur et al. and Morrison et al. in 2010 and 2012 respectively $(16,17)$.

The equilibrium of coagulation and fibrinolysis may compromise in traumatic shock and trauma-related hemorrhagic shock (18-20). Moreover, transfusion-related complications such as transfusion reactions, acute lung injury etc. could further complicate trauma patients receiving blood products (21-24). Thus, Tranexamic acid would reduce transfusion needs and may decrease morbidity and mortality in traumatic patients in hemorrhagic shock (25-27).

In the present study, we wanted to assess the effects of intravenous Tranexamic acid in reducing mortality and transfusion needs in trauma patients with significant hemorrhage. To our knowledge, this is the first study to investigate the effects of Tranexamic acid on bleeding control in Trauma patients in Iranian population.

\section{Methods}

In a randomized-controlled trial, we assessed the effects of Tranexamic acid on mortality and transfusion needs in traumatic patients with significant hemorrhage. The study was conducted at Imam Reza Hospital, Tabriz University of Medical Sciences, Tabriz, Iran. The study period was 16 months from January 2015 to April 2016. The entire patients were selected from Tabriz Imam Reza Hospital. This hospital is a level one trauma center and is the main and referral trauma hospital in East Azerbaijan province. During the study period, trauma patients were assessed for eligibility by our inclusion and exclusion criteria. Sixty patients were selected and were allocated to case and control groups. Each group contained 30 patients.

The inclusion criteria were patients between 15-50 years of age, systolic blood pressure (SBP) less than $90 \mathrm{mmHg}$ or heart rate more than 110 per min or both, trauma to admission interval less than eight hours, and not being in need of emergent surgical intervention. The exclusion criteria were patients younger than 15 years of age, patients older than 50 years of age, having contraindication to receive Tranexamic acid (pregnancy, known thromboembolic events, defective color vision, history of vascular occlusive disease, hyper-coagulopathy, history of allergic reaction and history of angioedema), and being in need of emergent surgical intervention. 
Study patients were divided into two groups of case and control groups. Randomization was conducted by www.randomizer.org. Figure 1 illustrates the follow diagram for randomized allocation of patients during the study. We administered Tranexamic to patients of case group within eight hours from trauma. Tranexamic acid was administered in $1 \mathrm{~g}$ dose (two $500 \mathrm{mg}$ vials) infused by $100 \mathrm{ml}$ of saline. Then, another $1 \mathrm{~g}$ dose was administered during eight hours. Tranexamic acid vials were products of Caspian Tamin Company (Tranexip 500 mg; 5 cc vials). For the patients in control group, placebo was administered. Placebo was consisted of $100 \mathrm{cc}$ of saline and $10 \mathrm{cc}$ of distilled water.

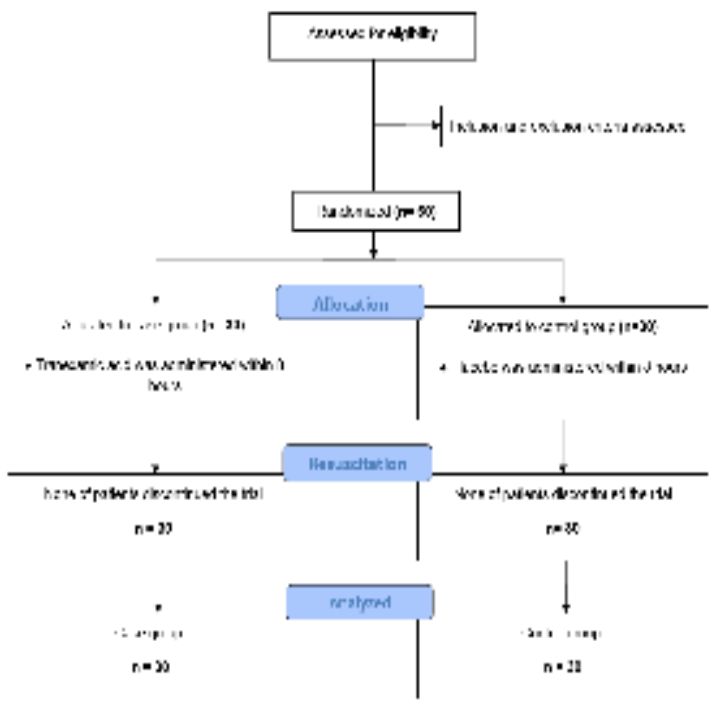

Figure 1: Follow diagram of study

patients.

The outcomes of patients were assessed during hospital admission, discharge, and one-month after their admission. Duration of admission, intensive care unit (ICU) stay and mortalities were recorded and assessed in study patients. The extent of transfusion was adjusted by the rate of ongoing bleeding. After bleeding control, serum hemoglobin concentration of 10 $\mathrm{g} / \mathrm{dL}$, platelet count of 100'000 in 1 microliter of blood, and international normalized ratio
(INR) of $<2$ were target levels for cessation of administration of packed cells, platelets and FFP respectively. Normal saline was used as the only crystalloid fluid in all study patients. Albumin was also administered in patients with albumin level less than $3 \mathrm{~g} / \mathrm{dL}$. Bicarbonate solutions were also administered in patients with metabolic acidosis and arterial blood $\mathrm{pH}$ less than 7.1. Central venous pressure (CVP) was maintained $10-12 \mathrm{~cm} \mathrm{H}_{2} \mathrm{O}$ in all study patients in case and control groups.

Standard trauma care was conducted to all study patients in case and control groups based on Advanced Trauma Life Support (ATLS). All trauma procedures including $A B C$ priorities, fluid therapy and resuscitation, intubation, fracture fixations, mechanical bleeding control and other essential strategies were conducted to all study patients. The only difference between case and control groups was administration of Tranexamic acid. Background variables were age, sex, time of trauma, type of trauma, and history of previous disease. Systolic blood pressure (SBP), pulse rate (PR), Glasgow coma scale (GCS), rate of administration of blood products (packed red cells, FFP and platelets), ICU admission, admission days, surgery and mortality were also recorded. All patients were visited and followed by chief-residents of surgery from admission to discharge and one-month after their admission. The patients were evaluated for complications of Tranexamic acid administration during the study.

The study was conducted in a doubleblind research setting. The patients were unaware of their study group and were assessed by surgical residents and attending physicians by group numbers (group 1=case 
group; group 2=control group). The investigators were also unaware of patients' intervention (Tranexamic acid or placebo). All data was collected by surgery residents and attending physicians and informed consent was obtained from patients. In the case of loss of consciousness or intubation, informed consent was obtained from patients' first degree relatives. All informed consents were obtained by surgery residents and attending physicians. The protocol of this study was accepted by research deputy of Faculty of Medicine and Vice Chancellor Office of Tabriz University of Medical Sciences, Tabriz, Iran. The study data were analyzed by SPSS 16.0 software. T-test, Fisher's exact probability test and chi-square test were used for analysis. P-values less than 0.05 were considered to be statistically significant.

\section{Results}

Thirty patients were assessed in each group of study. The intervention was administration of Tranexamic acid. Background variables were compared between two groups. These included age, sex, trauma type, interval from trauma to emergency department admission, pulse rate $(P R)$, systolic blood pressure (SBP), GCS, and respiratory rate (RR). Outcomes were also assessed and compared between case and control groups. These included blood products administration (packed red cells, FFP and platelets), ICU administration, surgical ward administration, being in need for surgery and mortality. Table 1 illustrates background variables in case and control groups. There was not any significant difference between background characteristics of two study groups $(p>0.05)$.

\begin{tabular}{|c|c|c|c|}
\hline & 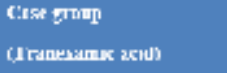 & 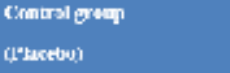 & p-ralni: \\
\hline 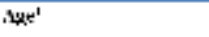 & its lv.1 & $3.0 \quad$ IV.S & $p-0.15$ \\
\hline \multirow[t]{2}{*}{$\sin ^{2}$} & 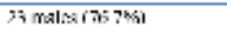 & 72 malss (7子 i\$s & $p-075$ \\
\hline & $\because$ jeuules $(22.3 \%)$ & $s$ [enusles (-6;\%) & \\
\hline \multirow[t]{2}{*}{ n'auma t:pe' } & 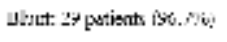 & 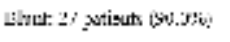 & p v.01 \\
\hline & $\begin{array}{l}\text { Carlant:al } 1 \text { paikanl } \\
\text { (f) } 4451\end{array}$ & 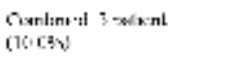 & \\
\hline 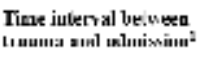 & 1.31 ..3 lours & $1.1+1.3$ bouss & $p-0.67$ \\
\hline Pubtu rat: pler minuale? & $121: 146$ & $1300+51$ & $p=\$ 24$ \\
\hline Systelse bloso plesent & $\$ 12 \quad \leq .2$ & s.t. $\quad .3$ & P $\quad 0.21$ \\
\hline$c c s$ & $13.1-2.3$ & $2 \cdot 1.9-1.2$ & P 0.21 \\
\hline Revipirakary rals. & $120-2.9$ & $120-12$ & $p=n s$ \\
\hline
\end{tabular}

Mean packed cell administration was $6.0 \pm 1.5$ and $6.0 \pm 1.2$ units in case and control groups respectively. T-test did not find any significant difference in packed cell administration in two study groups $(\mathrm{p}=0.99)$. FFP administration was also $2.5 \pm 1.4$ and $3.0 \pm$ 1.0 units in case and control groups respectively. The difference was not significant $(p=0.09)$. Platelet administration was $0.4 \pm 0.2$ and $1.3 \pm 0.3$ in case and control groups respectively. The difference in platelet administration was statistically significant $(p=$ 0.01).

Mean admission in surgical ward was $6.6 \pm 3.4$ and $8.0 \pm 4.8$ days in case and control groups respectively. The difference was not significant $(p=0.22)$. Admission more than 28 days was seen in two patients in case group and in five patients in control group. Mean ICU admission was $4.6 \pm 0.7$ and $5.8 \pm 0.8$ days in two study groups respectively. The difference was not significant $(p=0.26)$.

Four patients (13.3\%) necessitated surgery in case group while seven patients (23.3\%) in control group underwent surgery. The difference was not significant (Chi-square; $p=0.32$ ). All surgeries were orthopedic 
operations in case group. Six surgeries were orthopedic and one surgery was thoracoscopic in control group.

The rate of mortality was $10.0 \%$ (three patients) and $13.3 \%$ (four patients) in case and control groups respectively. Fisher's exact probability test revealed the difference between mortality in case and control groups was not statistically significant $(p=0.5)$. Cause of death was brain injury in all three patients of case group (10\%). Two patients $(6.7 \%)$ of control group died because of bleeding. One patient $(3.3 \%)$ died of brain injury and one patient $(3.3 \%)$ died of multi organ failure (MOF) in control group. The difference between two group was not significant considering MOF, brain injury and bleeding $(p=0.5, p=0.61$ and $p=0.49$ respectively).

\section{Discussion}

We assessed the effects of Tranexamic acid administration in reducing mortality and transfusion needs in patients with significant hemorrhage. The rates of mortality were $10 \%$ and $13.3 \%$ in case (Tranexamic acid) and control (placebo) groups respectively. The difference was not statistically significant. Transfusion needs were also compared between two groups. Only platelet administration was lower in patients receiving Tranexamic acid. The difference between packed red cells and FFP administrations were not significant.

The most clinically important research on the role of Tranexamic acid in traumarelated hemorrhage was CRASH-2 study in 2010. This study evaluated the effects of early Tranexamic acid administration (bolus of $1 \mathrm{~g}$ in $10 \mathrm{~min}$ and then infusion of $1 \mathrm{~g}$ in 8 hours) on 28-day mortality, vascular complications and transfusion needs in adult patients. CRASH-2 study assessed 20211 patients from 274 hospitals in 40 countries. The conclusion was lower mortality rate $14.5 \%$ in Tranexamic acid group vs. $16 \%$ in control group). However, complications and transfusion needs were not affected by Tranexamic acid administration (27). Our study also did not reveal any difference in packed cells and FFP infusions in patients receiving Tranexamic acid and placebo. However, CRASH-2 study shows a significant decrease in mortality. It should be emphasized that assessment of specific mortalities within case and control groups in CRASH-2 study illustrates that mortality only differs in hemorrhage-related deaths. Brain injury and MOF related mortalities were similar in case and control groups. In our study, we also did not find any difference between two groups of study in specific mortality rates.

Based on CRASH-2 study, in a comprehensive review, Ker et al. declare that using Tranxeamic acid in patients with traumarelated bleeding could decrease mortality and is recommended (28). A number of other studies also recommend use of Tranxemaic acid in trauma-related hemorrhage due to its potential effects in reducing mortality $(6,29)$. However, our study did not reveal any decrease in mortality. This may be in part due to our limited number of study sample.

Morrison et al. reviewed 896 files of trauma victims retrospectively. They revealed that mortality rate was lower in patients who received Tranexamic acid. Rate of coagulopathy episodes was also decreased in these patients. However, transfusion needs were not affected (17). Napolitano et al. also indicate that 
Tranexamic acid could decrease mortality in trauma but it would not affect transfusion requirements (30). Our study showed a decrease in platelet use in Tranexamic acid group.

Although the literature review reveals lower mortality in trauma patients receiving Tranexamic acid (27-30), transfusion requirements are not affected significantly. This is a matter of controversial issue to understand the underlying mechanism which could decrease mortality rate. Tranexamic acid is an anti-fibrinolytic agent that inhibits plasmin. Plasmin is a pro-inflammatory agent which could activate monocytes, neutrophils and endothelial cells. Thus, regulation of inflammatory mechanisms by Tranxemaic acid may play a more important role in reducing mortality (31-37).

Our study did not show that Tranexamic acid could decrease mortality in patients with trauma-related hemorrhage. However, literature review illustrates that Tranexamic acid is of potential use and clinical interest in trauma bleedings. A number of other studies propose that patients' conditions should be assessed prior to administration of Tranexamic acid in trauma-related hemorrhages. Thromboelastography is a method of evaluation prior to Tranexamic acid use (38-43).

\section{Acknowledgements}

The authors would like to thank personnel of emergency department and surgical intensive care unit (SICU) of Tabriz Imam Reza Hospital, Tabriz, Iran for their kind cooperation.

\section{Conflicts of interest}

NONE

\section{References}

1. Sauaia A, Moore FA, Moore EE, Moser KS, Brennan R, Read RA, et al. (1995). Epidemiology of trauma deaths: a reassessment. J Trauma, 38(2), 185-193.

2. Lawson JH, Murphy MP. (2004). Challenges for providing effective hemostasis in surgery and trauma. Semin Hematol, 41(1 Suppl 1), 55-64.

3. Porte RJ, Leebeek FW. (2002). Pharmacological strategies to decrease transfusion requirements in patients undergoing surgery. Drugs, 62(15), 2193-2211.

4. Porte RJ, Molenaar IQ, Begliomini B, Groenland TH, Januszkiewicz A, Lindgren L, et al. (2000). Aprotinin and transfusion requirements in orthotopic liver transplantation: a multicentre randomised double-blind study. EMSALT Study Group. Lancet, 355(9212), 1303-1309.

5. Henry DA, Moxey AJ, Carless PA, O'Connell D, McClelland B, Henderson KM, et al. (2001). Anti-fibrinolytic use for minimising perioperative allogeneic blood transfusion. Cochrane Database Syst Rev, (1), CD001886.

6. Roberts I, Shakur H, Ker K, Coats T, collaborators C-T. (2012). Antifibrinolytic drugs for acute traumatic injury. Cochrane Database Syst Rev, 12CD004896.

7. Williams-Johnson JA, McDonald AH, Strachan GG, Williams EW. (2010). Effects of tranexamic acid on death, vascular occlusive events, and blood transfusion in trauma patients with significant haemorrhage (CRASH-2) A randomised, placebo-controlled trial. West Indian Med J, 59(6), 612-624.

8. Sorensen B, Fries D. (2012). Emerging treatment strategies for traumainduced coagulopathy. Br J Surg, 99 Suppl 140-50. 
9. Pusateri AE, Weiskopf RB, Bebarta V, Butler F, Cestero RF, Chaudry IH, et al. (2013). ranexamic acid and trauma: current status and knowledge gaps with recommended research priorities. Shock, 39(2), 121-126.

10. Kauvar DS, Wade CE. (2005). The epidemiology and modern management of traumatic hemorrhage: US and international perspectives. Crit Care, 9 Suppl 5S1-9.

11. Etxaniz A, Pita E. (2016). Management of bleeding and coagulopathy following major trauma. Rev Esp Anestesiol Reanim, 63(5), 289-296.

12. Henry DA, Carless PA, Moxey AJ, O'Connell D, Stokes BJ, Fergusson DA, et al. (2011). Anti-fibrinolytic use for minimising perioperative allogeneic blood transfusion. Cochrane Database Syst Rev, (3), CD001886.

13. Kenet G, Walden R, Eldad A, Martinowitz U. (1999). Treatment of traumatic bleeding with recombinant factor VIla. Lancet, 354(9193), 1879.

14. Boffard KD, Riou B, Warren B, Choong PI, Rizoli S, Rossaint R, et al. (2005). Recombinant factor VIla as adjunctive therapy for bleeding control in severely injured trauma patients: two parallel randomized, placebocontrolled, double-blind clinical trials. J Trauma, 59(1), 8-15; discussion 15-18.

15. Fox CJ, Mehta SG, Cox ED, Kragh JF, Jr., Salinas J, Holcomb JB. (2009). Effect of recombinant factor VIla as an adjunctive therapy in damage control for wartime vascular injuries: a case control study. J Trauma, 66(4 Suppl), S112-119.

16. collaborators C-t, Shakur H, Roberts I, Bautista R, Caballero J, Coats T, et al. (2010). Effects of tranexamic acid on death, vascular occlusive events, and blood transfusion in trauma patients with significant haemorrhage (CRASH-2): a randomised, placebo-controlled trial. Lancet, 376(9734), 23-32.

17. Morrison JJ, Dubose JJ, Rasmussen TE, Midwinter MJ. (2012). Military Application of Tranexamic Acid in Trauma Emergency Resuscitation (MATTERs) Study. Arch Surg, 147(2), 113-119.

18. Brohi K, Cohen MJ, Davenport RA. (2007). Acute coagulopathy of trauma: mechanism, identification and effect. Curr Opin Crit Care, 13(6), 680-685.

19. Brohi K, Cohen MJ, Ganter MT, Schultz MJ, Levi M, Mackersie RC, et al. (2008). Acute coagulopathy of trauma: hypoperfusion induces systemic anticoagulation and hyperfibrinolysis. J trauma, 64(5), 1211-1217; discussion 1217.

20. Lapostolle F, Sebbah JL, Couvreur J, Koch FX, Savary D, Tazarourte K, et al. (2012). Risk factors for onset of hypothermia in trauma victims: the HypoTraum study. Crit Care, 16(4), R142.

21. Levy JH. (2006). Massive transfusion coagulopathy. Semin Hematol, 43(1 Suppl 1), S59-63.

22. Bailey AM, Baker SN, Weant KA. (2014). Tranexamic Acid for Trauma-Related Hemorrhage. Advanced Emergency Nursing Journal, 36(2), 123-131.

23. Cervia JS, Sowemimo-Coker SO, Ortolano GA, Wilkins K, Schaffer J, Wortham ST. (2006). An overview of prion biology and the role of blood filtration in reducing the risk of transfusion-ransmitted variant Creutzfeldt-Jakob disease. Transfus Med Rev, 20(3), 190-206.

24. Cap AP, Baer DG, Orman JA, Aden J, Ryan K, Blackbourne LH. (2011). Tranexamic acid for trauma patients: a critical review of the literature. J Trauma, 71(1 Suppl), S9-14.

25. Kluger R, Olive DJ, Stewart AB, Blyth CM. (2003). Epsilon-aminocaproic acid in coronary artery bypass graft surgery: preincision or postheparin? Anesthesiology, 99(6), 1263-1269.

26. Levi M, Levy JH, Andersen HF, Truloff D. (2010). Safety of recombinant activated factor VII in randomized clinical trials. N Engl J Med, 363(19), 1791-1800.

27. collaborators C-, Roberts I, Shakur H, Afolabi A, Brohi K, Coats T, et al. (2011). The importance of early treatment with tranexamic acid in bleeding trauma patients: an exploratory analysis of the CRASH-2 randomised controlled trial. Lancet, 377(9771), 1096-1101, 1101 e1091-1092.

28. Ker K, Kiriya J, Perel P, Edwards P, Shakur H, Roberts I. (2012). Avoidable mortality from giving tranexamic acid to bleeding trauma patients: an estimation based on WHO mortality data, a systematic literature review and data from the CRASH-2 trial. BMC Emerg Med, 123. 
29. [No authors listed] (2013). Trauma and severe bleeding. Tranexamic acid within one hour to reduce mortality. Prescrire Int, 22(140), 189-190.

30. Napolitano LM, Cohen MJ, Cotton BA, Schreiber MA, Moore EE. (2013). Tranexamic acid in trauma: how should we use it? J Trauma Acute Care Surg, 74(6), 1575-1586.

31. Medcalf RL. (2007). Fibrinolysis, inflammation, and regulation of the plasminogen activating system. $J$ Thromb Haemost, 5 Suppl 1132-142.

32. Syrovets T, Simmet T. (2004). Novel aspects and new roles for the serine protease plasmin. Cell Mol Life Sci, 61(7-8), 873-885.

33. Jimenez JJ, Iribarren JL, Lorente L, Rodriguez JM, Hernandez D, Nassar I, et al. (2007). Tranexamic acid attenuates inflammatory response in cardiopulmonary bypass surgery through blockade of fibrinolysis: a case control study followed by a randomized double-blind controlled trial. Crit Care, 11(6), R117.

34. Jimenez JJ, Iribarren JL, Brouard M, Hernandez D, Palmero S, Jimenez A, et al. (2011). Safety and effectiveness of two treatment regimes with tranexamic acid to minimize inflammatory response in elective cardiopulmonary bypass patients: a randomized double-blind, dosedependent, phase IV clinical trial. J Cardiothorac Surg, 6138.

35. Godier A, Roberts I, Hunt BJ. (2012). Tranexamic acid: less bleeding and less thrombosis? Crit Care, $16(3), 135$.

36. Guerriero C, Cairns J, Perel P, Shakur H, Roberts I, collaborators Ct. (2011). Cost-effectiveness analysis of administering tranexamic acid to bleeding trauma patients using evidence from the CRASH-2 trial. PLoS One, 6(5), e18987.

37. Bailey AM, Baker SN, Weant KA. (2014). Tranexamic acid for traumarelated hemorrhage. Adv Emerg Nurs J, 36(2), 123-131; quiz 132-123.

38. Roberts I. (2016). Fibrinolytic shutdown: fascinating theory but randomized controlled trial data are needed. Transfusion, 56 Suppl 2S115-118.

39. Moore EE, Moore HB, Gonzalez E, Chapman MP, Hansen KC, Sauaia A, et al. (2015). Postinjury fibrinolysis shutdown: Rationale for selective tranexamic acid. J Trauma Acute Care Surg, 78(6 Suppl 1), S65-69.

40. Gando S, Sawamura A, Hayakawa M. (2011). Trauma, shock, and disseminated intravascular coagulation: lessons from the classical literature. Ann Surg, 254(1), 10-19.

41. Ralley FE. (2015). Tranexamic acid: When is enough (data) enough? Can J Anaesth, 62(11), 1149-1152.

42. Gerstein NS, Kelly SP, Brierley JK. (2015). Yet Another Tranexamic Acid-Related Thrombotic Complication. J Cardiothorac Vasc Anesth. 30(3):e21-2.

43. Farrell NM, Wing HA, Burke PA, Huiras P. (2015). Addition of tranexamic acid to a traumatic injury massive transfusion protocol. Am J Health Syst Pharm, 72(12), 1059-1064. 